\title{
Developing comprehensive and evidence-based policy and guidelines for antenatal and postnatal care in KwaZulu-Natal
}

\author{
Prudence Ditlopo \\ Mantshi Menziwa \\ Population Council \\ Saiqa Mullick \\ Population Council \\ Saumya RamaRao \\ Population Council \\ Janet Dalton
}

See next page for additional authors

Follow this and additional works at: https://knowledgecommons.popcouncil.org/departments_sbsr-rh

Part of the Demography, Population, and Ecology Commons, International Public Health Commons, Maternal and Child Health Commons, and the Women's Health Commons How does access to this work benefit you? Let us know!

\section{Recommended Citation}

Ditlopo, Prudence, Mantshi Menziwa, Saiqa Mullick, Saumya RamaRao, Janet Dalton, Dolly Nyasulu, Mags Beksinska, and Busi Kunene. 2008. "Developing comprehensive and evidence-based policy and guidelines for antenatal and postnatal care in KwaZulu-Natal," FRONTIERS Final Report. Washington, DC: Population Council. 


\section{Authors}

Prudence Ditlopo, Mantshi Menziwa, Saiqa Mullick, Saumya RamaRao, Janet Dalton, Dolly Nyasulu, Mags Beksinska, and Busi Kunene 


\title{
Developing comprehensive and evidence-based policy and guidelines for antenatal and postnatal care in Kwazulu- Natal
}

\author{
Population Council \\ Prudence Ditlopo \\ Mantshi Menziwa \\ Saiqa Mullick \\ Saumya Ramarao
}

\section{Provincial Department of Health, Kwazulu-Natal, Maternal Child and Women's Health \\ Janet Dalton \\ Dolly Nyasulu
Reproductive Health and HIV Research Unit
Mags Beksinska
Busi Kunene

May 2008

This study was funded by the President's Emergency Plan for AIDS Relief (PEPFAR) and by the generous support of the American people through the United States Agency for International Development's South Africa Mission (USAID/SA) under the terms of Cooperative Agreement No. HRN-A-00-98-00012-00, and In-house Project 8811 53089. The opinions expressed herein are those of the authors and do not necessarily reflect the views of the United States Government.
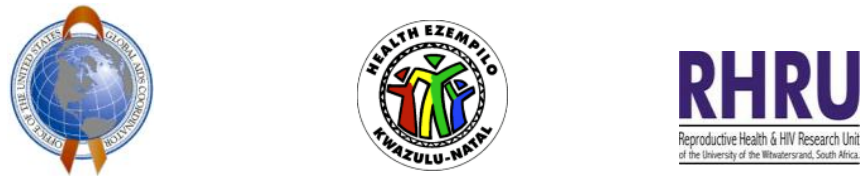


\section{TABLE OF CONTENTS}

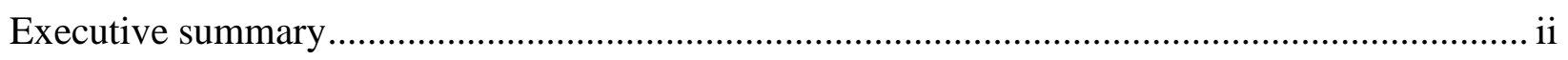

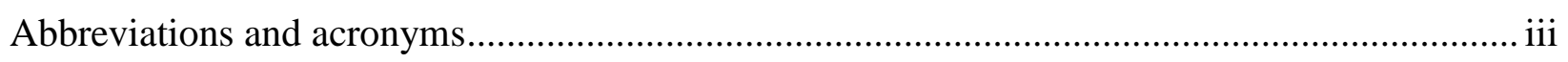

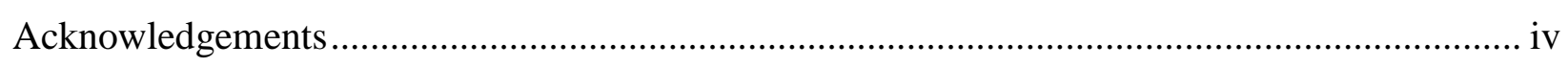

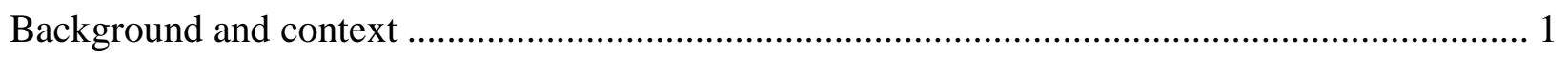

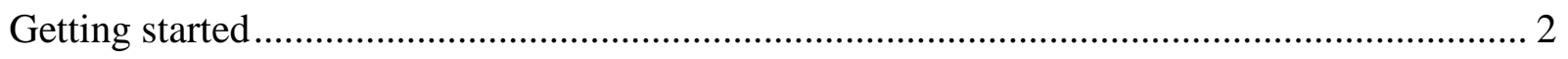

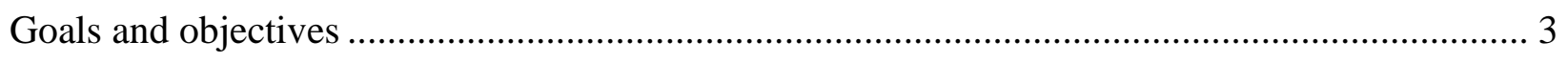

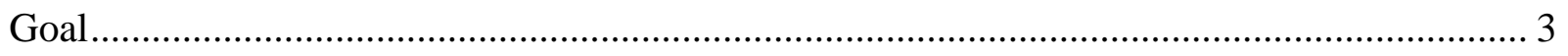

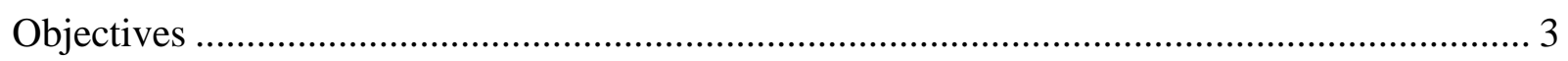

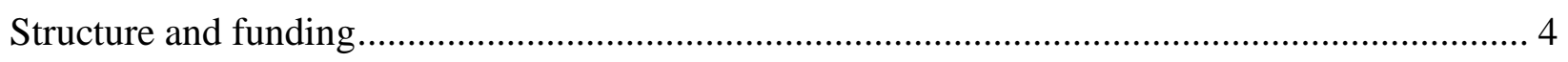

The policy and guidelines development process ........................................................... 5

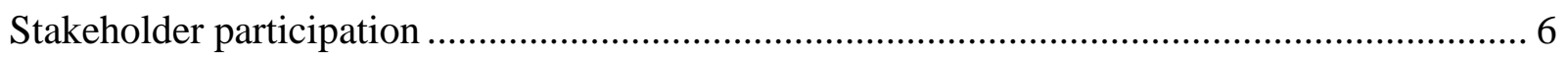

Theoretical piloting of the guidelines ........................................................................ 10

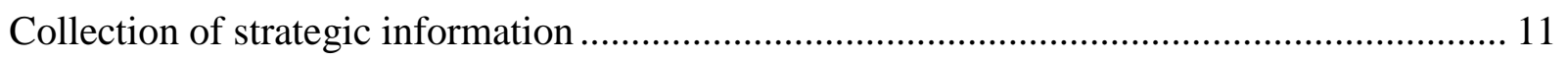

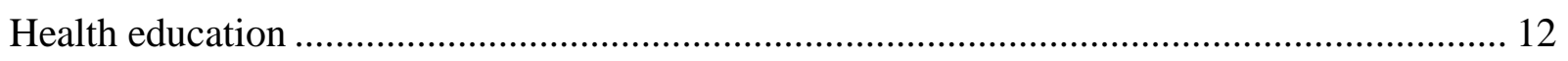

Development/adaptation of training materials and job aids ........................................... 13

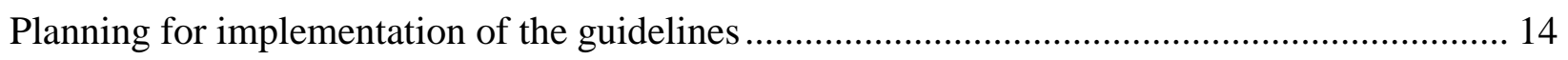

Training strategy and identification of training teams ................................................... 14

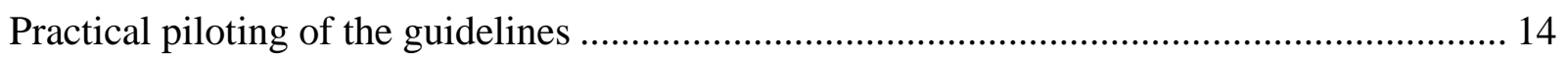

Finalization of the policy and guidelines ................................................................. 14

Lessons learned from the participatory process .............................................................. 15

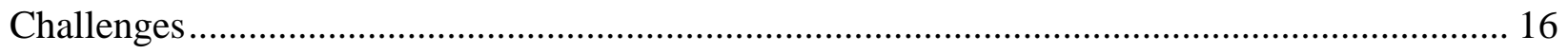

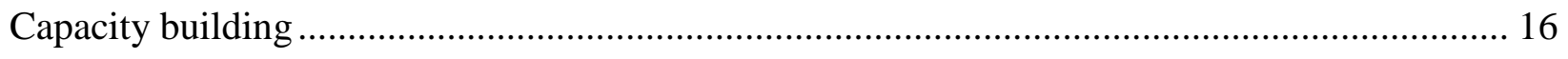

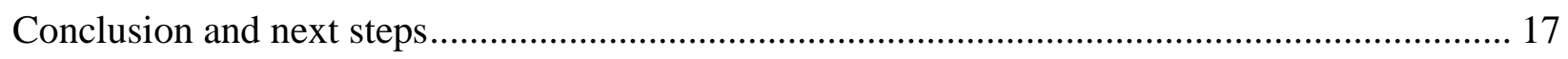




\section{EXECUTIVE SUMMARY}

Despite the magnitude of the HIV epidemic in South Africa, current maternity care guidelines do not address HIV services such as voluntary counseling and testing (VCT), prevention of motherto-child transmission (PMTCT), antiretroviral drugs (ARVs) or management of HIV-positive women pre- and post delivery in an integrated manner. Although new services relating to HIV have been rolled out, they have not been systematically integrated into antenatal and postnatal care. In addition to gaps in the national policy, a provincial policy guiding ANC and PNC does not exist in Kwazulu-Natal. In May 2004, the KZN Maternal Child and Women's Health (MCWH) department requested Population Council's USAID-funded FRONTIERS project for technical assistance in developing standardized and comprehensive antenatal and postnatal care policies and guidelines and supportive training and educational materials.

The aims and objectives of this project were to: support the development of a comprehensive evidence-based antenatal and postnatal care program in KZN; consolidate lessons learned and evidence around delivery of comprehensive ANC and PNC; revise provincial guidelines to enable comprehensive ANC and PNC care services that address PMTCT, partner involvement, syphilis screening, focused visits and ARVs; develop supportive systems for implementing new guidelines, monitoring and evaluation tools, job aides and training materials; and build the capacity of health care providers and program, thereby strengthening monitoring of ANC and PNC services.

FRONTIERS adopted a participatory process, ensuring buy-in and ownership at all levels through the involvement of all key stakeholders. This approach has not only ensured that local, national and international research-based evidence fed into the development of the provincial antenatal and postnatal care policies and guidelines, but also that buy-in and ownership were generated at all levels.

In April 2006, the draft guidelines and monitoring tool underwent a 'pre-field test' to review content, layout, relevance, user friendliness and appropriateness of the guidelines. The guidelines were then re-edited and a number of key conceptual changes made. It is worth mentioning that these guidelines are aimed at providing guidance primarily, but not exclusively, for uncomplicated pregnancies at primary health care level.

The process to date and the draft policy and guidelines will be shared at a Regional Safe Motherhood forum, bringing together national and provincial program managers and implementers, academics, donors and NGO representatives from South Africa, Swaziland, Lesotho and Kenya. The Provincial MCWH/STI and PMTCT coordinators, with help from the technical assistance team, will then develop a training plan. The DOH has already committed itself to securing funding to support rolling out the new guidelines province-wide.

In order to assess the impact of the guidelines, FRONTIERS will collaborate with the provincial $\mathrm{DOH}$ and other implementing partners in the province to conduct a pilot testing to evaluate the effectiveness of the new guidelines and to ensure that they are relevant, accepted and can be applied across a variety of settings. Pilot implementation of the new guidelines is set for June 2008. The provincial DOH is committed to supporting a province-wide rollout of training after the pilot-testing. 


$\begin{array}{ll}\text { ABBREVIATIONS AND ACRONYMS } \\ \text { ANC } & \text { Antenatal Care } \\ \text { ARVs } & \text { Antiretroviral Drugs } \\ \text { CTOP } & \text { Choice on Termination of Pregnancy } \\ \text { DOH } & \text { Department of Health } \\ \text { KZN } & \text { KwaZulu-Natal } \\ \text { MCWH } & \text { Maternal Child and Women's Health } \\ \text { MMR } & \text { Maternal Mortality Rates } \\ \text { NGO } & \text { Non-Governmental Organization } \\ \text { PMTCT } & \text { Prevention of Mother to Child Transmission } \\ \text { PHC } & \text { Primary Health Care } \\ \text { PNC } & \text { Postnatal care } \\ \text { PC } & \text { Population Council } \\ \text { RHRU } & \text { Reproductive Health and HIV Research Unit } \\ \text { STIs } & \text { Sexually Transmitted Infections } \\ \text { TA } & \text { Technical Assistance } \\ \text { TOP } & \text { Termination of pregnancy } \\ \text { WHO } & \text { World Health Organization } \\ \text { VCT } & \text { Voluntary Counseling and Testing }\end{array}$




\section{ACKNOWLEDGEMENTS}

We would like to thank those who have participated in the policy and guideline development process in KwaZulu-Natal. Particular appreciation goes to Ms. Janet Dalton and Ms. Dolly Nyasulu from the KZN Provincial MCWH program for their leadership and commitment to the process.

We would also like to thank the many nurses and program managers from the eleven districts in KZN for participating in the stakeholders meetings and for their inputs as the various drafts of the guidelines were developed. Special thanks also go to the various key informants who provided their expert opinions for the various topic areas.

Thanks go to all the pregnant women and postpartum women who participated in the study.

We would also like to recognize the financial support from United States Agency for International Development (USAID) for providing PEPFAR funding for this important initiative. 


\section{BACKGROUND AND CONTEXT}

South Africa is performing well on certain selected maternal health process indicators: antenatal care attendance is high and has remained over $90 \%$ since 1998 . Yet maternal mortality rates (MMR) have remained high, with reported maternal deaths in South Africa increasing from 676 in 1998 to 1173 in 2004. Rates increased markedly between 1998 and 2004 in many provinces. Whether this was due to improved reporting or increased deaths is not known (175-200/100 000 live births). HIV rates amongst antenatal clients are also high and have risen exponentially from less than $1 \%$ in 1990 to $30.2 \%$ in 2006.

The HIV prevalence in pregnant woman attending antenatal clinics increased slightly between 2004 (29.5\%) and 2005 (30.2\%). An HIV-positive woman may be prone to greater risk during a pregnancy due to her compromised immune status and due to procedures conducted during labor and delivery. The Saving Mothers report for the 2002-2004 triennium indicates that HIV testing of women improved from $37.6 \%$ in the previous triennium to $50 \%$. This means that of women who died - half had been tested for HIV. The target for HIV testing in antenatal care had been set for $80 \%$ and therefore there still is need for improvement in these figures.

Furthermore, non-pregnancy related infections (NPRI) were the leading cause of maternal death between 2002-2004. In addition, this proportion has increased from 31.4\% in the 1999-2001 triennium to $37.4 \%$ and this also has resulted in an increased proportion of deaths in the indirect category. AIDS contributed to over half $(53.1 \%)$ of the deaths classified as NPRI and this was predominately due to respiratory failure or immune system failure. Pregnancy related sepsis following a viable pregnancy also affected a high proportion of HIV-positive women in the 2002-2004 triennium. In 53.3\% of the cases the status was unknown but of those who were tested, 68\% were HIV-infected. The maternal death assessment process cannot confirm that a death is related to HIV or AIDS unless a woman has been tested; therefore, there is an assumption that there is a considerable underestimation of AIDS-related maternal deaths. The highest proportion of estimated maternal deaths (243/100 000) (DOH 2002) and the highest prevalence of HIV in ANC clients $(39.1 \%, 2006)$ is found in KwaZulu-Natal (KZN), and AIDS is now the leading cause of maternal mortality in KZN.

Antenatal care, delivery and postnatal care need to place a particular focus on screening for and appropriate management of communicable diseases, such as HIV, during pregnancy and beyond. Although antenatal care attendance is high, issues around the services rendered, such as timing of the first visit and providers' attitudes need, to be critically assessed as they are also important if optimum quality of care is to be achieved.

Staff shortages, training and staff motivation appear to be particular issues in maternal health care services. The introduction of the prevention of mother-to-child transmission of HIV programme and, more recently, the recommendation that women should be initiated into the antiretroviral programme during antenatal care, have placed additional challenges on the maternal health services. Postnatal care in South Africa has not been adequately prioritised as a maternal health care service. With high maternal and perinatal mortality rates found in the postnatal period there needs to be guidelines and systems put in place to ensure that care of the woman and her newborn goes beyond the delivery. 
Despite the magnitude of the HIV epidemic in South Africa, current maternity care guidelines do not address HIV services such as voluntary counseling and testing (VCT), prevention of motherto-child transmission (PMTCT), antiretroviral drugs (ARVs) or management of HIV-positive women pre- and post delivery in an integrated manner. The guidelines also do not adequately cover TB screening and treatment (despite an increase in the prevalence of TB and resistant strains), monitoring of nutritional status of pregnant and lactating women, sexual advice for pregnant women, gender-based violence issues, male involvement (particularly regarding the results of the Men in Maternity study undertaken in the Province), health education about birth preparedness, and postnatal visits (especially in light of the number of maternal deaths occurring in the post natal period). In addition, a provincial policy guiding antenatal care (ANC) and postnatal care (PNC) does not exist in KZN.

Recent studies in the province, conducted by the Population Council's Frontiers in Reproductive Health (FRONTIERS) project, have shown that a lack of protocols, guidelines and job aids for ANC services, as well as little policy support, were obstacles to providing quality services in the province's public sector facilities. The objective of this report is to document the process of developing evidence-based policy and guidelines and to share lessons learned. It is aimed primarily at program managers who can apply and build on this approach in other efforts to develop policy and guidelines.

\section{Getting started}

The lack of protocols and guidelines for ANC services and the need for job aides have been raised by ANC providers as impediments to providing quality services. Consequently, following a meeting with various provincial DOH representatives in March 2004 at which specific weaknesses in the existing guidelines were identified, the KZN Maternal Child and Women's Health (MCWH) program asked FRONTIERS for technical assistance in developing comprehensive antenatal and postnatal guidelines and supporting materials for providing standardized delivery of quality antenatal and postnatal care, including integration of HIV services, in primary care settings. The Population Council was also requested to provide some technical support to the process of planning and monitoring implementation. Specific support was requested to develop the following:

- A provincial antenatal and postnatal policy for KZN;

- Provincial comprehensive guidelines for antenatal and postnatal care in KZN;

- A provincial strategy for monitoring, supervision and evaluation to strengthen comprehensive ANC and PNC;

- A set of job aides to support implementation of the guidelines;

- Training materials that support implementation;

- Implementation of quality of care for pregnant and post natal women. 


\section{GOALS AND OBJECTIVES}

\section{Goal}

To support the development of a comprehensive antenatal and postnatal care program in KZN in order to:

- Maintain women's health during pregnancy;

- Decrease maternal morbidity and mortality;

- Decrease perinatal mortality;

- Establish a postnatal framework for the care of the mother and baby.

\section{Objectives}

The objectives at the initial phase of the project were to:

1. Consolidate lessons learned and evidence around the delivery of comprehensive antenatal and postnatal care;

2. Develop a comprehensive, evidence-based provincial antenatal and postnatal policy;

3. Revise provincial guidelines to enable comprehensive antenatal and postnatal care services that address PMTCT. These services include:

- full ARV regimes,

- partner involvement,

- syphilis and other STI screening,

- five focused visits and screening for TB in every women,

- increased monitoring of anemia,

- fetal growth monitoring,

- inclusion of basic genetic screening, domestic violence and mental health screening.

The follow-up phase of this project included:

1. Conducting a pre-field test and pilot implementation of the new guidelines;

2. Developing supportive systems for implementation of the guidelines, including monitoring and evaluation tools, job aides and training materials; and

3. Building the capacity of health care providers and program managers to use and implement the revised policy and guidelines and to strengthen monitoring of antenatal and postnatal services. 


\section{STRUCTURE AND FUNDING}

The Population Council's FRONTIERS and Horizons programs have a history of collaboration with the provincial MCHW unit in KZN in the area of maternal health, having completed three studies together: the Men in Maternity (MIM) study; the Ulundi Comprehensive ANC study; and the KZN Provincial Situational Analysis. Much information generated by these projects has been used to feed into the policy and guideline development process.

The project was led by the KZN MCWH program in collaboration with the Reproductive Health and HIV Research Unit (RHRU) of the University of the Witwatersrand, and the Provincial STI, PMTCT, Nutrition and HIV and AIDS Programmes. The University of KwaZulu-Natal Departments of Obstetrics \& Gynaecology and Community Health also collaborated. The contribution of the two Community Health Registrars is acknowledged.

FRONTIERS and the RHRU provided technical assistance through participation in a core team that led the policy and guideline development process, through provision of funding for obtaining stakeholder and key informant and community inputs, and through documentation and sharing of lessons learnt, including the identification of key research and other evidence to guide a systematic process to:

- Ensure that local, national and international research-based evidence feeds into the development of the provincial antenatal and postnatal care policies and guidelines.

- Ensure that buy-in and ownership are generated at all levels through the involvement of all key stakeholders.

This was achieved through a series of meetings and forums to consult with a broad range of stakeholders. This initiative was driven by the Provincial DOH which also co-funded the activities. In addition, the DOH agreed to fund all implementation costs for pre field-testing necessary to develop the guidelines, and is interested in supporting implementation of a province-wide training effort as a follow up to this project. 


\section{THE POLICY AND GUIDELINES DEVELOPMENT PROCESS}

Policy and guideline development is commonly a top-down process. Those actually charged with implementation are usually unlikely to contribute to the process and often will be the last group to be informed that new policies and guidelines are about to be implemented. The concepts are internalized at the top level but may not filter down and have little impact on the actual day-today activities in the health facilities. The relevance, acceptability and feasibility of policy and guidelines are often not examined with stakeholders and are often developed for an urban environment yet are applied across a variety of settings.

The process of policy and guideline development for antenatal and postnatal care in KZN was initiated by the KZN MCWH directorate and in the initial stages it was decided that these guidelines would be primarily focusing on uncomplicated deliveries at primary health care to tertiary level. During the initial stages it was agreed that a participatory approach would be used and various groups of stakeholders were identified and involved in the process at all stages. Despite this, there had to be incremental decisions made by the core team during the process, particularly around the methodology and timelines for inclusion of various stakeholders and including inputs.

One important decision that was taken after the process began was to conduct focus group discussions with beneficiaries of the policy, i.e. pregnant and post partum women, to ensure community input. It is recognized however, that these community level inputs included women who had used public sector antenatal and postnatal services and excluded a small proportion of women who do not use these services at all or access private sector services.

In addition, capacity building was seen as an integral part of the process from the initial stages, as it is regarded as a requirement for the successful decentralization of health services. Health care providers were thus invited to participate in the policy development from the outset. 


\section{Stakeholder participation}

A participatory approach for ensuring that buy-in and ownership were generated at all levels through the involvement of all key stakeholders as described in Figure 1.

\section{Figure 1: The Policy and Guidelines Development Process}

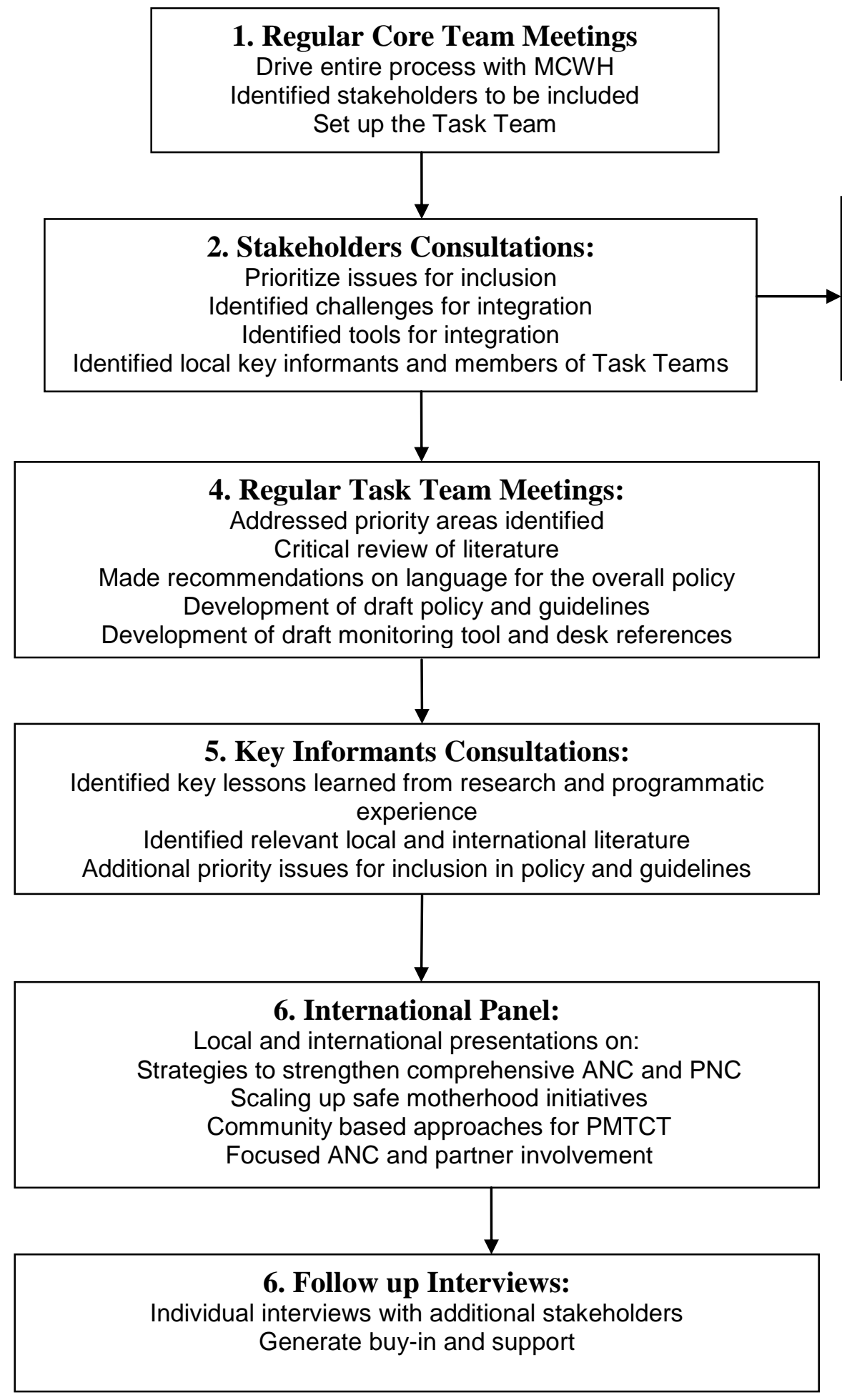


A number of groups were identified and defined to inform and participate in the consultative process at various stages. These were:

- The Core Team

- Stakeholders

- Task Teams

- Key Informants.

\section{Core Team}

The first step was to set up a core team, consisting of a project director, project co-directors and the technical assistance team - key staff from the Department of Health working in the areas of MCWH, Nutrition, STI and PMTCT, RHRU and FRONTIERS. The role of the Core team was to lead the policy and guidelines development process.

Core team members included the key individuals within the MCWH provincial program responsible for implementation of quality antenatal and postnatal care, key experts from RHRU who had been involved in the MIM and Ulundi ANC studies, and FRONTIERS staff with appropriate expertise. In addition to having the relevant experience, all core team members agreed to provide a regular and substantial time commitment over an extended period and the provincial MCWH program also committed itself to providing co-funding for the policy and guideline development.

\section{Stakeholder Consultation}

During August and September 2004, stakeholders and key informants from all 11 districts (rural and urban) in KZN were consulted and involved in establishing priority areas for inclusion in the policy and guidelines, relevant tools for integration of maternal services, as well as identifying potential challenges for integration of services.

Loosely defined, stakeholders are "users" or "implementers" of the guidelines and consisted of district medical officers, primary health care nurses, district MCWH co-ordinators, midwives, advanced midwives, nurse educators, and representatives from program management. This group also included parties who had an interest in the outcome of the project.

Key informants are subject experts who helped to inform and guide the process, particularly with regard to specific technical areas. Stakeholders and key informants also helped to identify relevant provincial and district staff who formed several task teams arranged according to a number of themes identified for special consideration and planning. Despite their busy schedules and the concomitant challenges, meetings were well attended and all districts were represented.

\section{Key Informants}

Key informants are subject experts who helped to inform and guide the process, particularly with regard to specific technical areas. Key informants consisted of 15 academics and researchers. These experts included individuals who were conducting research in the field of antenatal and postnatal care, including conducting trials on PMTCT, individuals with experience in 
implementing and developing tools for the provision of antenatal and postnatal services, expert obstetricians linked to university institutions, academics teaching community and public health, laboratory specialists, pediatricians and representatives of nurse training institutions.

In particular, the University of KwaZulu-Natal Medical School Centre for Rural Health, Department of Obstetrics \& Gynecology, and Community Health provided academic input to the policy and guidelines. The National Department of Health also was kept informed of the process and content through their medical obstetric consultant.

The role of this group was to inform the guidelines and policy process of latest trends and research results that were regarded as significant and identify best practice. They also brought their expertise, opinion and experience to the process. This was done in two group meetings.

Due to limited availability of key informants, the core team conducted follow-up visits with the meeting attendees and additional key informants to generate buy-in and support and identify key lessons learnt from research and programmatic experience.

It is worth noting that all geographic areas and service delivery levels in the province were represented at these meetings and that the attendance of representatives of various government departments (TB, nutrition, health promotion, STI, PMTCT, Community Health Work, genetics, gender, and HIV/AIDS) contributed to an unusually collaborative environment within the DOH.

\section{Task Teams}

Following the initial stakeholder consultation, five task teams were set up to evaluate family planning/pre-conception care, antenatal care, post natal care, community participation and health systems, in order to:

- review the existing guidelines and prepare draft wording for the revised guidelines,

- make recommendations on language for the overall policy, and

- propose key indicators for monitoring.

There was concern that sufficient attention be paid to the supportive systems necessary (e.g., health information systems, supervision, equipment, correct placement and utilization of staff, hours of service and resource allocation/utilization, among others), as well as placing much emphasis on addressing the role of the community and the need for community involvement in both the development process and successful implementation of policy and guidelines. This was addressed by holding four focus groups with pregnant women at facilities.

The task teams also made recommendations on overall language use and key indicators for monitoring. Task team members further assisted with the development of the first draft of the policy and guidelines as well as draft monitoring tools. The task teams consisted of representatives from provincial MCWH, STI and PMTCT units, RHRU, FRONTIERS, midwifery college representative, support services (e.g., laboratory and transport representatives), academia, and other selected stakeholders. 
The results of these task team meetings were summarized in a discussion document, which guided the process and served as a resource for the KZN task teams, as well as being shared with other countries in the region interested in conducting a similar process. Representatives from the $\mathrm{DOH}$ in Swaziland have participated in the activities and core team meetings and will continue to participate as a means for replicating the process in Swaziland. The next activity in the process will be an international panel to present results from research on scaling up safe motherhood initiatives, community based approaches for PMTCT, focused ANC, and partner involvement, as well as provide examples and evidence from experiences in other countries in the region, this activity will create linkages that could be expanded to a more formal regional network in the future. There is already interest in expanding this process to other countries in the region from the USAID Southern Africa Regional HIV/AIDS Program, which has supported the participation of the Swaziland DOH.

This process was followed by a further key informants' consultation during which key lessons learned from research and programs, as well as relevant local and international literature, were identified. Additional priority areas were also noted for inclusion in the draft policy and guidelines.

This process was presented during an international panel where inputs were obtained from a larger local and international audience. A questionnaire was then developed and supported by individual follow up on key technical areas with key informants. A consultant was hired to consolidate the guidelines and a further draft of the Provincial policy and guidelines were developed.

Despite the process being driven by one unit - the provincial MCWH unit - the diversity and inclusiveness of the process transcended the core team directing the process. In addition to the international members mentioned above, the core team included representatives from the STI and PMTCT units, as well as several advanced midwives and chief professional nurses from clinics in the surrounding areas of iLembe, eThekweni, and uMgungundlovu districts. This meant that discussions were grounded in practicality and relevant to both urban as well as rural realities.

The priority issues and challenges identified were remarkably similar across the groups. The need for policy and guidelines that support a continuum of care for women from pre-conception to postpartum and family planning was emphatically emphasized by all, as well as one that comprehensively addresses a woman's needs no matter at what point she enters into the system.

Participants identified a set of areas as needing in-depth review by task teams: preconception, family planning, Choice on Termination of Pregnancy (CTOP); ANC; PNC; health systems; and community participation and health promotion. Because it is seen as relevant at all points in the continuum, it was decided that HIV and AIDS issues (including prevention, VCT, PMTCT, treatment, care and support) would be incorporated into each of the areas by the task teams. Information on how HIV issues are being integrated was shared among the groups at periodic task team meetings.

Several task team meetings were held over a period of a year, during which all six task team members were brought together for a day at a time - tasks for the day were identified by the core 
team who would normally meet prior to the task team meetings to discuss the facilitation and updates to be provided at each meeting. Most task teams functioned well, although several participants represented their organizations and therefore continuity (participation from the same individual) could not always be guaranteed at all times.

\section{Theoretical piloting of the guidelines}

In April 2006, the draft guidelines and monitoring tool underwent an initial 'pre-field test', comprising a stakeholder review of the content and issues around implementation. The final draft of the policy and guidelines, along with a questionnaire, were disseminated to 78 stakeholders and key informants, comprising staff from five clinics in three districts surrounding Durban (iLembe, eThekweni, and uMgungundlovu) asking them to comment on:

- $\quad$ content (accuracy, inclusions, exclusions);

- flow of text;

- $\quad$ relevance to content (relationship between policy and guidelines);

- $\quad$ style and language; and

- format.

Key comments received were:

\begin{tabular}{|l|l|}
\hline \multirow{4}{*}{ Strengths } & Information/content is evidence based \\
\cline { 2 - 3 } & Information is comprehensive and relevant to current practice \\
\cline { 2 - 3 } & Language used is simple and understandable \\
\hline \multirow{5}{*}{ Wecommendations } & $\begin{array}{l}\text { There is too much text information that could be summarized in flow charts or } \\
\text { tables }\end{array}$ \\
\cline { 2 - 3 } & $\begin{array}{l}\text { Guidelines are too long and not user-friendly as they cannot be used as quick } \\
\text { reference }\end{array}$ \\
\cline { 2 - 3 } & There is a lot of repetition \\
\cline { 2 - 3 } & Use of tables will promote better and quick reference to the guidelines \\
\cline { 2 - 3 } & Risk factors should be highlighted \\
\cline { 2 - 3 } & Guidelines need to be shortened \\
\cline { 2 - 3 } & Staff turnover and shortage need to be taken into consideration \\
\cline { 2 - 3 } & The guidelines need to be incorporated into midwifery training \\
\cline { 2 - 3 } & $\begin{array}{l}\text { There is a need for in-service training for all professional nurses in all clinics at the } \\
\text { grassroots level to implement the guidelines effectively }\end{array}$ \\
\hline
\end{tabular}


Following these results the guidelines were edited and a number of key conceptual changes were made as follows:

1. The guidelines were organized by a reduced number of goal-oriented visits (focused antenatal care)

2. Postnatal care was included and emphasized

3. Partner involvement was included and emphasized

4. HIV prevention, testing and PMTCT was integrated into each visit

5. Guideline format included history taking, examination and advice given for each visit

6. Referral systems were included and emphasized

7. The guidelines integrated all key aspects of maternal health into each visit

8. The guidelines were arranged according to visit and highlight key actions, advice and examinations to be conducted at each visit.

\section{Collection of strategic information}

As part of the process to inform the development of the policy and guidelines, stakeholders recommended that focus group discussions be conducted with pregnant women to identify their maternal health needs. Although this was not part of the initial proposal, both stakeholders and core team members felt that this would be an important component to inform the process. The purpose of the focus groups was:

1. To explore clients' perspective on health needs of pregnant women

2. To explore the experiences of pregnant women with regard to service delivery and quality of care during their pregnancy (from first visit to post natal care)

3. To get suggestions from client themselves about what they think could be done to improve services offered to pregnant women

4. To explore clients' perceptions on required HIV related services for both ANC and PNC clients

5. To explore clients' perceptions on anticipated changes to ANC and PNC as a result of implementation of the new guidelines.

Four focus groups were held in four sites:

- Stanger - urban (central KZN)

- Jozini - rural (north KZN)

- Ixopo - rural (south KZN)

- Escourt - urban (west KZN).

Participants were between the ages of 15 and 35 years and each group consisted of six to eight participants. Nurses assisted with recruitment of potential participants in some clinics. 
The focus groups explored areas such as:

- knowledge of maternity care;

- health education;

- knowledge of STIs;

- experiences of labour and delivery;

- partner involvement during pregnancy;

- experiences of postnatal care;

- perceptions regarding the use of contraception after delivery; and

- attitudes towards changes in the new policy.

Feedback from the focus groups can be summarized as detailed below:

\section{Knowledge of ANC and Maternity Care}

1. Participants seemed to know what ANC entails, but there were variations about when to start ANC, from two months to four months.

2. For teenagers, the delays in attending ANC were due to hiding their pregnancies; it was not clear what caused delays for the older women.

3. In one focus group, respondents indicated that the nurses advised them to come again in three months time; they said that they were even returned by the nurses if they came earlier than that.

4. Almost all respondents were concerned that the nurses do not explain to them the reasons for doing certain ANC procedures such as taking urine, BP, taking blood, doing palpations. They also indicated that the nurses do not also explain the outcome of such test.

5. Most respondents reported that they would prefer to have a section in the clinic dedicated to pregnant women instead of being mixed up with the general patients. They emphasized that it is embarrassing for them walking around with urine in front of other general patients.

6. Respondents felt that confidentiality and privacy were not maintained in the clinics.

7. Respondents indicated that they had to wait for approximately three to five hours before being seen by the providers only to be seen for five minutes.

\section{Health education}

Health education was provided in all the clinics except in Ixopo. However, in one clinic, respondents highlighted that health education was mainly given when they agreed to have an HIV test. CTOP was not discussed with the pregnant women in all the clinics and women seemed to be judgmental about it due to their religious and moral beliefs. There seemed to be lack of knowledge on the recognition of danger signs.

\section{Knowledge of STIs}

Most respondents did not know much about STIs. The majority indicated that nurses do not usually check them for STIs; nurses rely on information told by the respondents, even if clients are sometimes embarrassed to disclose that they have an STI symptom. They reported that they would prefer to be checked by the nurses. Polygamous relationships seemed to be acceptable for most respondents. 


\section{Labour and Delivery}

Transport seemed to be the major problem during delivery. One focus group reported that there was no ambulance available and getting transport from the community to the hospital was expensive. Nurses' attitudes during delivery seemed to be a huge problem. Some women indicated that they were not given food after delivery.

\section{Partner Involvement during Pregnancy}

Most respondents did not seem to be keen to have their partners accompanying them for ANC or even being around during delivery. They said that they would rather prefer to have their aunts or mothers but only during delivery not for ANC.

\section{Postnatal Care}

Respondents all agreed that the nurses cared more about the babies than themselves after delivery. One respondent indicated that she gave birth at home due to transport problems but when she came to the clinic the following day, the nurses only checked the baby and not her. Even when the mother informs the nurses that she is not feeling well she is not checked.

\section{Use of Contraception after Delivery}

The majority of the respondents reported that nurses did not give them an opportunity to choose a method of contraception after delivery, stating that nurses give them the three-month injection Depo Provera; even if they have a reaction to it. Some respondents were told about dual protection.

\section{Changes in Policy}

There seemed to be ambivalence about the number of visits. Some respondents preferred more visits because they felt that they would know earlier if the baby was not okay, while others felt that ongoing transport to the clinics was a problem.

\section{Recommendations}

It was suggested that pregnant women should have their own maternity unit or section, to ensure confidentiality and privacy.

Following the focus group analysis, the policy and guidelines were further refined to emphasize marketing of ante- and postnatal care providing more information to communities and pregnant women. The issues of birth preparedness and other education were outlined in the education and counseling sections.

\section{Development/adaptation of training materials and job aids}

Stakeholders were involved in identifying existing guidelines, training manuals and protocols that needed to be reviewed or adapted. They agreed that a consultant would be hired to review the documents identified and to develop a new training manual based on the newly developed 
policy and guidelines, and according to an agreed format. The consultant would also assist in planning for implementation.

\section{PLANNING FOR IMPLEMENTATION OF THE GUIDELINES}

\section{Training strategy and identification of training teams}

Once the final version of the policy, guidelines, monitoring and training module is complete, a workshop will be held with the trainers, supervisors and selected professional nurses to identify a provincial training team. The training team will consist of representatives from various programs and all members will be expected to have a role and mandate to provide training in the province. The process to date and the draft policy and guidelines will be shared at a Regional Safe Motherhood forum bringing together national and provincial program managers and implementers, academics, donors and NGO representatives from South Africa, Swaziland, Lesotho and Kenya.

The Provincial MCWH/STI and PMTCT co-ordinators will then develop a plan and identify resources from the $\mathrm{DOH}$ budget for training on the new guidelines. The technical assistance team will provide support and guidance for preparation of the plan. The DoH has already committed itself to securing funding to support rolling out of the new guidelines with a province-wide training strategy. Trainings will be conducted on two levels:

- Practical level: Midwives, Obstetricians and Gynecologists, doctors involved in maternal care, community health workers and program managers.

- Supervisory level: Supervisors will be extensively targeted.

\section{Practical piloting of the guidelines}

During this phase, health care providers from one or two well-resourced facilities from the surrounding districts of iLembe, eThekweni, and uMgungundlovu will be trained by the DOH using the newly developed training package and will be asked to use the guidelines under "normal" clinic conditions for one month. After the trial period, they will be invited for a workshop to discuss their experiences with the use of the guidelines. Their experiences will provide information on how well people are able to use the guidelines, what obstacles were encountered and recommendations for minimum requirements for actual implementation. A proposal for a structured field test will be developed for implementation at a later date. A member of the core team will take notes and a tape recording will be made of the providers' feedback. The notes and transcription will be analyzed and used to inform any revisions of the guidelines and job aides as well as the training materials and strategies.

\section{Finalization of the policy and guidelines}

The final version of the guidelines will be launched in Durban in June 2008. National and provincial stakeholders, including members of the core team, and key informants, will attend. 
The policy, guidelines and job aides will be disseminated widely within the province through the DOH training workshops and other relevant provincial and district level workshops and forums. In addition, presentations will be made nationally and provincially at conferences, workshops and forums for advocacy purposes as well as to disseminate relevant aspects of the project including key issues, key findings and project progress.

Key national stakeholders and select DOH staff from other interested provinces will be invited to participate in the stakeholders and key informants workshops and review drafts of the policy, guidelines and monitoring tool. An anticipated outcome of involving national stakeholders is that the guidelines/tools developed may be adapted for national use.

\section{LESSONS LEARNED FROM THE PARTICIPATORY PROCESS}

The following lessons were learned from the process of policy and guidelines development:

- Participatory processes can and should take several forms and require a certain level of flexibility, commitment, discipline and time management, since a number of groups have to be brought together and tasks managed. There needs to be a central coordinating group (core team) to manage and guide the overall process.

- It is important to define who can add value where and how. It is more effective to focus on tasks with a defined audience rather than calling too big a group to all meetings.

- Obtaining inputs is an important part of the process and requires time commitment, however; participants are not always able to set aside more time to consolidate inputs or to do any substantial amount of documentation or writing of relevant documents. It is advisable to use consultants or core team members for this.

- Participation of various stakeholders allows for broader and more comprehensive thinking.

- The inclusion of key informants from across all geographic areas and service delivery levels was particularly useful.

- The focus group discussions with pregnant women to identify maternal health needs were an additional element which informed the process and added valuable insight in further refining the policy and guidelines. Surprisingly, some of these women felt that rather than having fewer ANC visits, they would prefer more visits as this would increase their chances of coming into contact with someone who was not judgmental and who had a positive attitude.

- Informed knowledge of stakeholders' area of expertise, team spirit and inter-stakeholder relationships is essential to allow for conducive and smooth running of the meetings.

- Participatory processes still need an individual "in charge" or directing the process; there is a need for a catalyst or supportive organization to keep track of the process and to ensure that meetings are happening.

- Participatory processes require generous timelines and well defined direction for participants.

- The inclusion of experts in various fields (who often are very busy and focused on their area of expertise) can make priority setting and consensus on the scope of issues to cover more 
difficult and time consuming; however participation of various stakeholders allows for broader and more comprehensive thinking.

- Protocols and evidence were changing during the process, causing delays in the production, but ultimately improving the final product.

\section{CHALLENGES}

Developing the provincial policy and guidelines was time consuming due to the participatory approach. Furthermore, the inclusion of experts in various fields has been a challenge as they were often too busy to attend crucial meetings, thus delaying the process.

While FRONTIERS continuously ensured that key MCWH staff were driving the process, this is also a challenge as their availability is critical for key meetings to move the process forward. During 2004 and 2005, there was a measles outbreak in KZN and it was the responsibility of the MCWH Programme to co-ordinate the outbreak response. This caused a loss of momentum. During 2006 in particular, the PMTCT program fell under the MCWH directorate, which meant that key MCWH staff were tasked with additional responsibilities. Although this is good for integration purposes which is a crucial component of the guidelines, key core team members from MCWH had added responsibilities and were overwhelmed with the volume of work. As such, they had to shift their focus from the development of the policy and guidelines to concentrate more on the PTMCT area.

In order to ensure sustainability, this process has been driven from the onset by the KZN MCWH staff and it was hoped that this team would act as a resource to facilitate ongoing sharing of lessons learned. A great deal of change in management and reorganization has occurred in the KZN DOH in recent years and two key MCWH staff recently moved into new positions in the province. Although they are currently involved in the project, this has been a great loss for the project and their availability for crucial meetings has been a challenge.

\section{CAPACITY BUILDING}

Capacity building was a key component of developing this policy and guidelines for ANC and PNC in Kwazulu-Natal. Program managers at district level are seldom exposed to policy planning and development. As a result, they are often ill-prepared to be involved in program and policy development within their districts, region or province.

In order to build capacity and ensure sustainability, health care providers from five clinics in the surrounding areas of iLembe, eThekweni, and uMgungundlovu districts were invited from the outset to participate in the development of the policy and guidelines. This capacity building element is aimed at developing "future" managers.

Five advanced midwives or chief professional nurses were given specific tasks and roles to play and their clinics were involved in the pre-field tests. These clinics will also be the first to implement the guidelines. Staff from these clinics may also be identified to assist in the roll out of training and supervision activities in other areas after the launch. 


\section{CONCLUSION AND NEXT STEPS}

The participatory approach has not only ensured that local, national and international researchbased evidence fed into the development of the provincial antenatal and postnatal care policies and guidelines but that buy-in and ownership are generated at all levels through the involvement of all key stakeholders. In alignment with a National Human Resources Plan for Health, the Population Council will provide technical assistance to the MCWH for the province-wide rollout of the guidelines and job aides. 